\title{
Evaluation of a real-time method for monitoring volatile organic compounds in indoor air in a Japanese university
}

\author{
Hajime Hori • Sumiyo Ishimatsu • Yukiko Fueta • \\ Toru Ishidao
}

Received: 28 June 2012/ Accepted: 6 November 2012/Published online: 27 November 2012

(c) The Japanese Society for Hygiene 2012

\begin{abstract}
Objective Real time monitoring of total volatile organic compounds (TVOC) in rooms of Japanese university buildings was carried out to understand the temporal changes in actual indoor air quality.

Methods The TVOC concentrations in seven different rooms, consisting of a lecture room, a seminar room, three laboratories, a computer room and a library, were monitored continuously for $24 \mathrm{~h}$ via a personal VOC monitor equipped with a semiconductor gas sensor. An active sampling-thermal desorption method using stainless steel tubes packed with Tenax-TA was also carried out simultaneously to verify the usability of the monitor.

Results The TVOC concentrations measured by the personal VOC monitor were closely correlated with those measured by the active sampling method. The TVOC concentration in all rooms was generally low during the day and increased during the night. This concentration change corresponded to the ventilation cycle in the building. During the day, the TVOC concentration was generally lower than the provisional target criterion (advisable value) of indoor air quality in Japan $\left(400 \mu \mathrm{g} / \mathrm{m}^{3}\right)$. During the night, however, it exceeded this criterion in several rooms, especially during the summer season.

Conclusion The real-time monitor using a semiconductor gas sensor can provide useful data on changes in the TVOC concentration in indoor air with high sensitivity.
\end{abstract}

H. Hori $(\bowtie) \cdot S$. Ishimatsu $\cdot$ Y. Fueta $\cdot$ T. Ishidao

Department of Environmental Management, School of Health

Sciences, University of Occupational and Environmental Health,

1-1 Iseigaoka, Yahatanishi-ku, Kitakyushu,

Fukuoka 807-8555, Japan

e-mail: horih@med.uoeh-u.ac.jp
Keywords Volatile organic compounds - Indoor air · Semiconductor gas sensor - Active sampling .

Solid sorbent tube

\section{Introduction}

Volatile organic compounds (VOCs), including formaldehyde and acetaldehyde, are causal substances of the sick building syndrome (SBS) or multiple chemical sensitivities (MCS). In Japan, the Ministry of Health, Labor and Welfare recommended the indoor air criteria of the concentrations for 13 chemicals [1], and the Ministry of Education, Culture, Sports, Science and Technology [2] enacted procedures to measure the concentrations of formaldehyde and five VOCs, such as, toluene, xylenes, $p$-dichlorobenzene, ethyl benzene and stylene, as well as those of carbon dioxide, carbon monoxide, and suspended particulate matter, in rooms of school buildings.

For measurement standards, the International Organization for Standardization [3, 4] specifies an active sampling method using the solid sorbent tube packed with silica gel coated with 2,4-dinitrophenyl hydrazineliquid extraction-high performance liquid chromatography (HPLC) for formaldehyde, and a solid sorbent tube packed with Tenax-TA-thermal desorption-gas chromatography-mass spectrometry (GC/MS) or gas chromatography equipped with flame ionization detector (GC/ FID) for VOCs. Although these methods can measure individual aldehydes and VOCs separately with high sensitivity, the concentrations cannot be immediately known until instrumental analysis is completed.

Recently, several kinds of chemical sensors for gases and vapors, including semiconductor gas sensors and 
photoionization detectors, have been developed [5], and real-time monitors using such sensors have also been utilized for detecting VOCs [6]. Such monitors can measure a VOC concentration easily without any analytical instruments and technical skills. Although most of these monitors cannot measure individual compounds separately, the temporal change in the total VOC (TVOC) concentration can be continuously monitored because most of such monitors have data loggers.

In this study, real-time monitoring of the TVOC concentrations was continuously carried out using a personal VOC monitor equipped with a semiconductor gas sensor in seven rooms of a Japanese university for $24 \mathrm{~h}$, and daily and seasonal changes in the TVOC concentrations. In addition to real-time monitoring, an active sampling method was also carried out simultaneously, and measured values were compared with those of the personal VOC monitor.

\section{Methods}

\section{Sampling sites}

Seven different rooms, consisting of a lecture room, a seminar room, three laboratories, a computer room and a library, in a Japanese university were chosen for measuring VOCs. Except for the library, all rooms were in the same seven-story reinforced-concrete building that was built in 1997. The library is located in a different building that was built in 1978. Centrally controlled ventilation systems are installed in both buildings.

The lecture room has 24 sets of desks and chairs, one whiteboard with several felt-tip pens and one PC projector. The seminar room has five sets of desks and chairs, five laptop computers and printers, bookshelves, and a lot of books and stationary. Laboratory-1 is a room for conducting chemical and biological experiments and research. Many organic and inorganic compounds, including organic solvents, aldehydes, acids and alkalis, are stored in this room. There are also numerous laboratory instruments, including two gas chromatographs with auto-samplers and integrators, a refrigerator, a deep freezer and incubators. Two draft chambers and a clean bench are also installed in laboratory-1. Laboratory-2 is an engineering room that contains some machining tools, such as a small lathe and a machining center with personal computers and associated parts and components. Laboratory- 3 is an ergonomics room. There are ten long desks and 30 chairs in this room, as well as audio-visual (AV) equipment. In the computer room, there are more than 130 desktop computers and printers, as well as a large whiteboard with several felt tip pens. The library has a large amount of books, journals, microfilms, computers and copy machines, as well as desks, chairs, bookshelves. In addition to building materials, flooring and wallpaper, all of these instruments and fixtures in the rooms can be considered as TVOC emission sources.

In general, cigarette smoking is a large emission source in the indoor environment [7]. In this study, however, the effect of smoking on VOC concentrations is negligible because smoking is strictly prohibited not only in the buildings, but on the entire campus as well.

\section{Sampling methods}

A personal VOC monitor using a semiconductor gas sensor (FTVR-01, Figaro Engineering Inc., Osaka, Japan) was used for real-time monitoring of VOCs. This monitor has a data logger, and it can store the VOC concentration, temperature and relative humidity for up to $24 \mathrm{~h}$ at 1 -min intervals. The total VOC (TVOC) concentration is displayed in the monitor window. The concentration range of this monitor is from 0 to $9,999 \mu \mathrm{g} / \mathrm{m}^{3}$ and the detection limit and resolution of the sensor are $1 \mu \mathrm{g} / \mathrm{m}^{3}$.

Active sampling was also carried out simultaneously for laboratory- 1 and the seminar room at the same sampling points. Simultaneous measurement was also carried out at a residential living room in order to verify whether the VOC monitor can be applied to a room that would likely have different emission conditions compared with the university buildings. Environmental air was introduced into a stainless steel tube packed with Tenax-TA at a flow rate of $0.5 \mathrm{ml} / \mathrm{min}$ for $30 \mathrm{~min}$. Collected VOCs were desorbed with a thermal desorber (Turbo Matrix TD, Perkin Elmer, Waltham, MA), and the concentrations were determined by a GC/MS (GCMS-QP5050, Shimadzu, Kyoto, Japan) equipped with a capillary column (DB-WAX, $50 \mathrm{~m} \times 0.25 \mathrm{~mm}$, Agilent Technologies Inc., Santa Clara, CA). The detection limit of toluene was $1 \mathrm{ng}\left(0.07 \mu \mathrm{g} / \mathrm{m}^{3}\right)$. The TVOC concentration was determined as a toluene equivalent value; that is, the total chromatogram area was converted to the toluene concentration using a toluene calibration curve.

In order to investigate seasonal changes in the TVOC concentration, sampling was carried out 3-11 times, depending on the rooms, during different seasons over 1 year (Table 1). The seminar room and laboratory- 1 were measured almost every month, and the other rooms were measured not monthly but seasonally. Sampling points were at least $1.5 \mathrm{~m}$ from the walls, and 1-1.2 m above the floor. Sampling was carried out when lectures and practicals were not performed, but students and staff had free access to the rooms during sampling. 
Table 1 Average TVOC concentrations measured in various rooms during the day (8:00-18:00) and night (18:00-8:00)

\begin{tabular}{|c|c|c|c|c|}
\hline \multirow[t]{2}{*}{ Room } & \multirow[t]{2}{*}{$\begin{array}{l}\text { Area } \\
\left(\mathrm{m}^{2}\right)\end{array}$} & \multirow[t]{2}{*}{$\begin{array}{l}\text { No of } \\
\text { samples }\end{array}$} & \multicolumn{2}{|c|}{$\begin{array}{l}\text { TVOC concentration } \\
\text { average } \pm \mathrm{SD}\left(\mu \mathrm{g} / \mathrm{m}^{3}\right)\end{array}$} \\
\hline & & & Daytime & Nighttime \\
\hline Lecture room & 54 & 4 & $100 \pm 29$ & $197 \pm 107$ \\
\hline Seminar room & 18 & 11 & $287 \pm 152$ & $511 \pm 172$ \\
\hline $\begin{array}{l}\text { Laboratory-1 } \\
\text { (chemical and } \\
\text { biological) }\end{array}$ & 120 & 11 & $219 \pm 89$ & $538 \pm 306$ \\
\hline $\begin{array}{l}\text { Laboratory-2 } \\
\text { (engineering) }\end{array}$ & 90 & 5 & $171 \pm 151$ & $240 \pm 265$ \\
\hline $\begin{array}{l}\text { Laboratory-3 } \\
\text { (ergonomics) }\end{array}$ & 120 & 3 & $187 \pm 5$ & $218 \pm 70$ \\
\hline Computer room & 276 & 6 & $140 \pm 70$ & $113 \pm 94$ \\
\hline Library & 2,480 & 6 & $174 \pm 71$ & $204 \pm 50$ \\
\hline
\end{tabular}

\section{Results}

Comparison of the TVOC concentration measured by the VOC monitor and active sampling method

The VOC monitor that we used was calibrated with toluene. Because the sensitivity of the sensor depends on the types of VOCs, the values measured by the VOC monitor will vary depending on the VOC components. To investigate the validity of the VOC monitor, simultaneous measurements by the VOC monitor and the active sampling method were carried out in three different rooms including a residential living room. The results are shown in Fig. 1. Both values were averages from $30 \mathrm{~min}$ of sampling. A good correlation was obtained between the two methods. Although the composition of VOCs was different in individual samples, the values obtained by the VOC monitor were in good agreement, only slightly higher (ratio: $1 / 0.923=1.08$ ), with those obtained by the active sampling method. This result suggests that this VOC monitor is capable of monitoring the TVOC concentration without considering the individual VOCs present. Therefore, the TVOC values measured by the VOC monitor were valid and the values displayed on the monitor were used without any corrections.

\section{Change in the 24-h TVOC concentration measured} by the personal VOC monitor

Figure 2 shows an example of the change in the TVOC concentration, temperature and relative humidity in a laboratory (laboratory-1) using the VOC monitor for $24 \mathrm{~h}$. Monitoring was started at 14:00 on May 8 and terminated at 14:00 the next day. The TVOC concentration was around $100 \mu \mathrm{g} / \mathrm{m}^{3}$ between 14:00 and 18:00. However, it began to increase at 18:00 and reached the highest concentration at

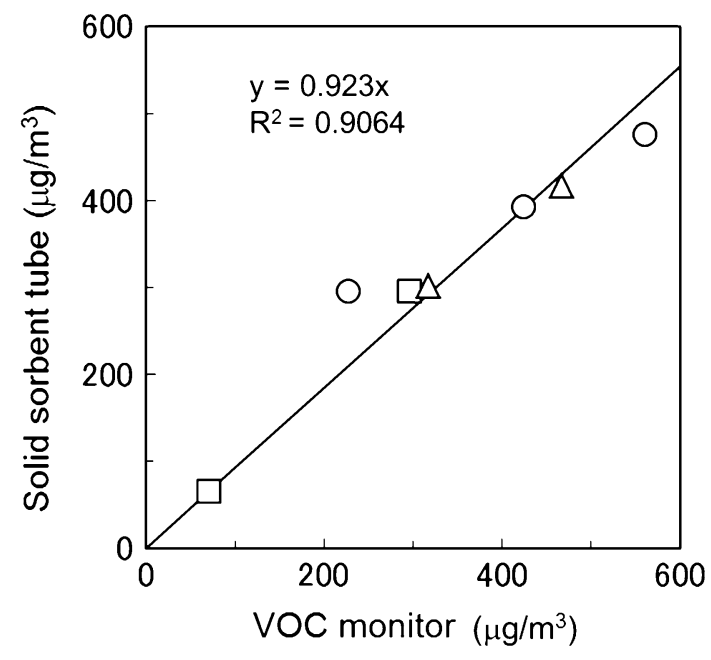

Fig. 1 Comparison of the TVOC concentrations measured with the VOC monitor and solid sorbent tube. Open circles laboratory, open squares seminar room, open triangles residential living room

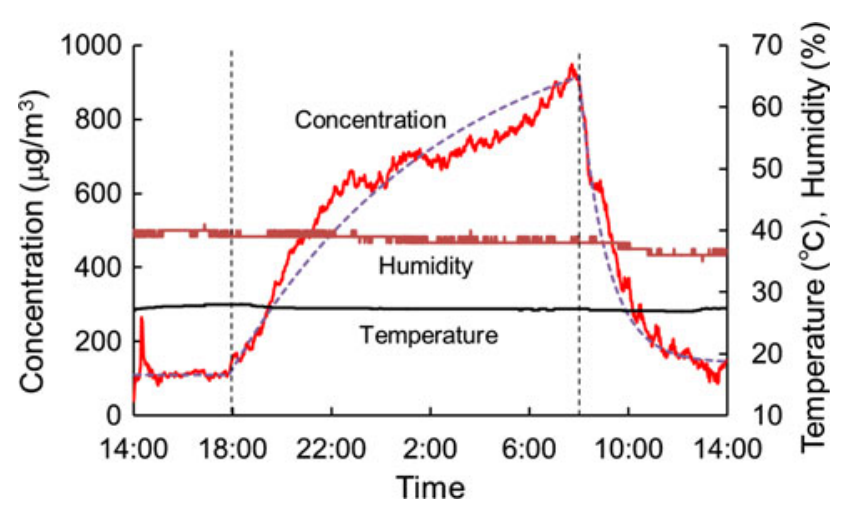

Fig. 2 Change in the VOC concentrations in laboratory-1 measured with the VOC monitor (May 8-9). Dashed line is the TVOC concentration estimated by a perfect mixing model with an air exchange rate of $0.12 \mathrm{~h}^{-1}$ during the night, $0.9 \mathrm{~h}^{-1}$ during the day and a TVOC emission rate of $40 \mathrm{mg} / \mathrm{h}$

around 8:00 the next morning. The concentration then decreased with time. This tendency was almost the same in all rooms and during all seasons, although the concentrations were different. The temperature and relative humidity did not change remarkably during the $24-\mathrm{h}$ monitoring. The dashed line represents the calculated TVOC concentrations, which will be discussed later.

\section{Seasonal change in TVOC concentration}

Figure 3 shows examples of the change in the TVOC concentrations in laboratory-1 (laboratory for chemical analysis). The TVOC concentration was low during each day, but it increased during the night. Even in the same room, the TVOC concentrations fluctuated daily. Figure 4 shows the seasonal change in average TVOC concentrations during 

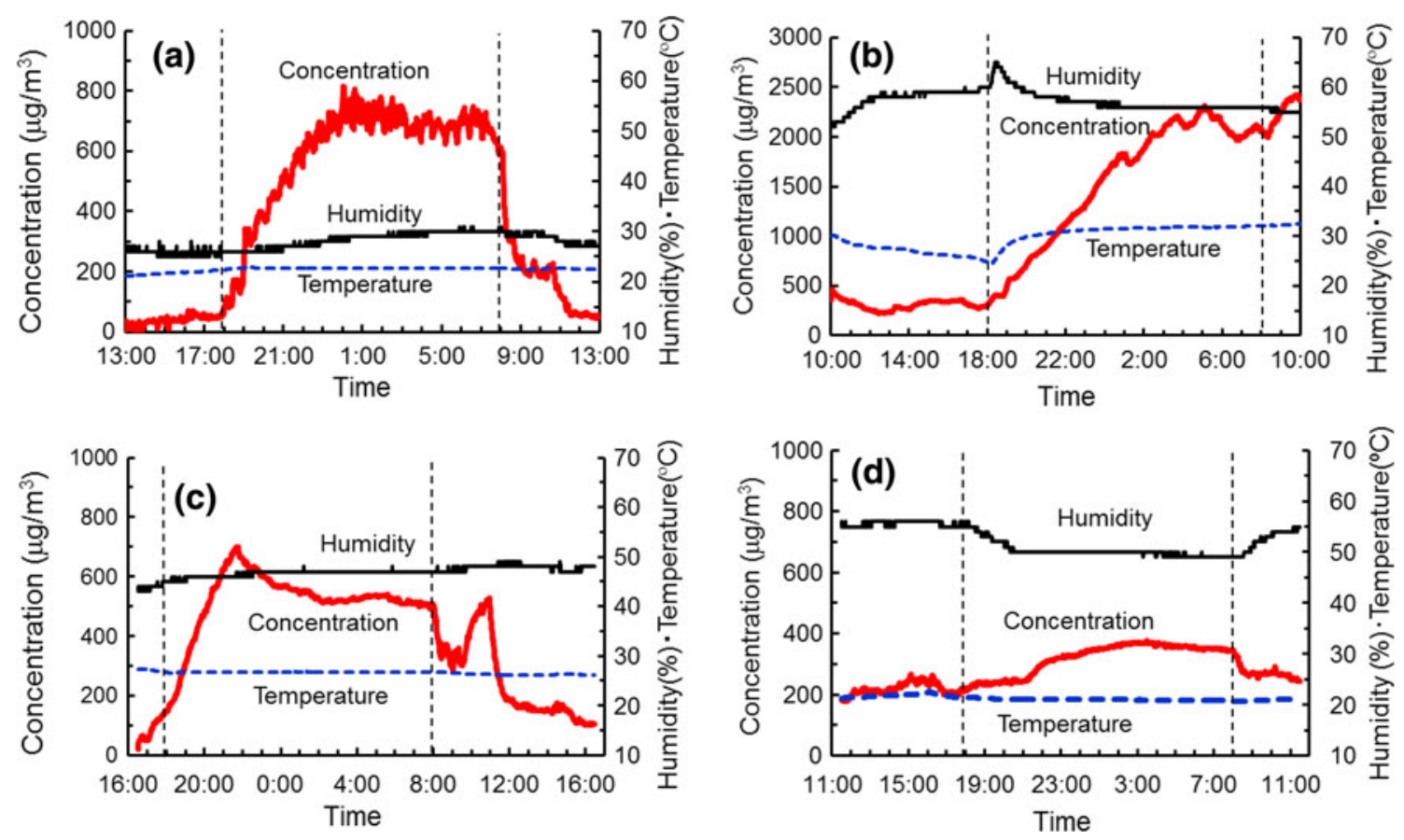

Fig. 3 Seasonal and temporal changes in the TVOC concentration, temperature and relative humidity in laboratory-1 Sampling was carried out on a April 24-25, b August 8-9, c October 15-16, d January 8-9

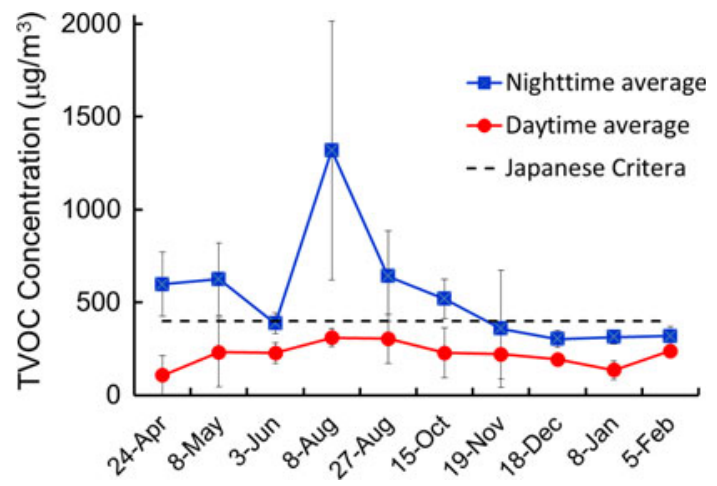

Fig. 4 Seasonal changes in the TVOC concentration in laboratory-1. Error bars indicate standard deviations of the TVOC concentrations

the day (8:00-18:00) and night (18:00-8:00). The VOC monitor obtained samples at 1-min intervals. Thus, 60 points $/ \mathrm{h} \times 10 \mathrm{~h}=600$ data points during the day, and $60 \times 14=840$ points data during the night were collected over 1 day $(24 \mathrm{~h})$ of sampling. The error bars indicate the standard deviations of 600 data points for the day and 840 data points for the night, respectively. In general, the TVOC concentration was high during the summer and low during the winter. The average TVOC concentration often exceeded the provisional target criterion (advisable value) for the TVOC concentration $\left(400 \mu \mathrm{g} / \mathrm{m}^{3}\right)$ [1], especially during summer nights, but it did not exceed target criterion during the day in all samples, except for unique cases, as shown in Fig. 5. The results obtained in all rooms are summarized in
Table 1 . The TVOC concentration was relatively high in the seminar room and laboratory-1, and it was low in the computer room and library. In all rooms, except for the computer room and library, the average TVOC concentration during the night was significantly greater than that during the day (Mann-Whitney $U$ test). In the computer room and library, on the other hand, the average TVOC concentrations were not always significantly different between the day and night.

Response characteristics of TVOC monitor at fluctuating VOC concentrations

Figure 5 also shows the results in laboratory-1. Sampling was carried out in November, but this measurement was not included in Fig. 4 and Table 1, because this was an unusual case in which chemicals including VOCs were intentionally used. The TVOC concentration during the first day was low, which was similar to that during other days, as shown in Figs. 2 and 3. However, during the 2nd day, the TVOC concentration remarkably increased between 09:00 and 11:00. Mice were dissected during this period and large amounts of ethanol were used. When the dissection was finished, the TVOC concentration decreased quickly, and returned to the initial level. The room temperature decreased during this period because cold outdoor air was introduced into the room instead of the exhaustion of indoor air by the draft chamber. When the dissection was finished, the draft chamber was switched off and the temperature began to simultaneously increase. Although 


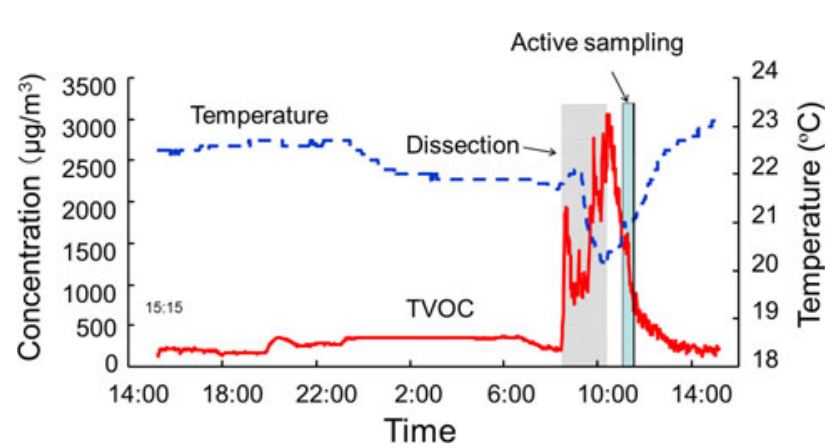

Fig. 5 Change in the TVOC concentration in laboratory-1 (November 26-27)

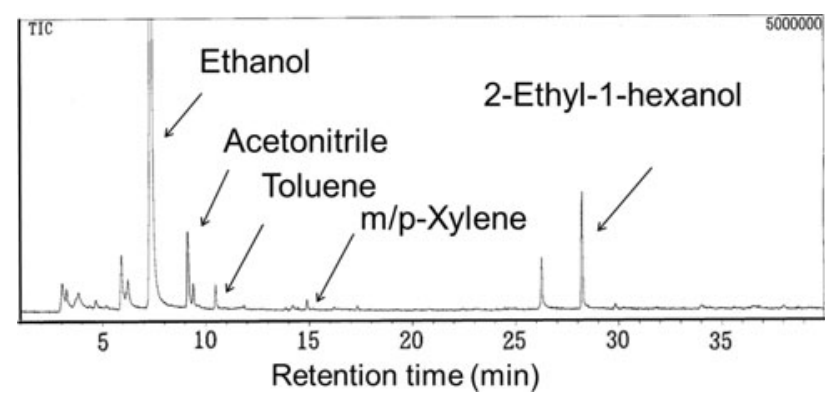

Fig. 6 GC/MS chromatogram of the VOC concentration in laboratory-1 during dissection of mice

the draft chamber in the room was operated in addition to the centrally controlled ventilation system, the sensor detected high concentration of TVOC. A major component of TVOC in this sample was ethanol, which was confirmed by a gas chromatogram (Fig. 6) obtained by the active sampling method that was conducted just after the dissection. In addition to ethanol, toluene and xylenes, which are commonly detected in indoor air [8], 2-ethyl-1-hexanol $(2 \mathrm{E} 1 \mathrm{H})$, which is also suspected as a cause of SBS [9-11], and acetonitrile were also detected.

\section{Discussion}

In the indoor environment, many VOCs are emitted from building materials [12] such as furniture [13]. In previous studies [14, 15], we measured the VOC concentrations including aldehydes in the same university buildings by the active sampling method using Tenax-TA tubes. Toluene, $m / p$-xylene, $2 \mathrm{E} 1 \mathrm{H}$, formaldehyde and acetaldehyde were commonly detected in 12 rooms. In these studies, we confirmed that the individual VOC concentrations were lower than those stipulated by the Japanese criteria [1, 2]. Because VOCs are a cause of SBS or MCS, the target VOC concentrations should be minimized. However, it is difficult to specify the target compound, and SBS may actually be a result of compounds [16]. Therefore, to reduce the risks of SBS or MCS, the reduction of not only individual compounds but also total VOC (TVOC) concentrations is very important [17].

In order to understand changes in the TVOC concentration, we continuously monitored the concentration for $24 \mathrm{~h}$ using a real-time VOC monitor equipped with a semiconductor gas sensor. When using VOC monitors, the validity of the monitors should be confirmed because the sensitivity of the sensors on VOCs may be different [18]. Figure 1 indicates that the correlation between the data by the VOC monitor and those by the active sampling method was good. The slope of the data from laboratory-1 was somewhat gentler than the regression line, suggesting that the values obtained by the VOC monitor were not always proportional to those obtained by the active sampling method. The reason for this result may be the difference in the VOC composition. Among the data from laboratory-1, the ratio of $2 \mathrm{E} 1 \mathrm{H}$ in TVOC was much different among the samples. When the ratio of $2 \mathrm{E} 1 \mathrm{H}$ in TVOC was high, the values obtained by the VOC monitor were lower than those obtained by the active sampling method. This suggests that the sensitivity of the sensor for $2 \mathrm{E} 1 \mathrm{H}$ was low. The concentration of $2 \mathrm{E} 1 \mathrm{H}$ was high after wax had been applied to the floor. The usual concentration of $2 \mathrm{E} 1 \mathrm{H}$ was not extremely high at this university [13,14], so we judged that this monitor could be used for TVOC monitoring in this study.

The VOC concentrations may change depending on the temperature, relative humidity, and air conditioning including ventilation [15]. The university buildings in which we measured the VOC concentrations have a centrally controlled air conditioning ventilation system. Ventilation starts at 8:00 and shuts down at 18:00. A part of the indoor air is exhausted, and the remaining indoor air is mixed with outdoor air and recycled in the buildings. In our study, the TVOC concentration was low during the day, but it began to increase at 18:00 and then decrease at 8:00, which was synchronized with the ventilation pattern of the university building. In most cases, the VOC concentrations were below a target value in Japan $\left(400 \mu \mathrm{g} / \mathrm{m}^{3}\right)$ during the day. During the night, however, the VOC concentration increased because the air conditioning systems were shut down. This fact indicates that the air conditioning system operates effectively at this university.

Menzies et al. [19] measured the TVOC concentrations in two office buildings (A, B) in Montreal at two ventilation levels. They took measurements during working hours $(8 \mathrm{~h})$ using the solid sorbent tube (charcoal) method from mid-April to late-May. The TVOC levels of building A (10 years old) were $160 \mu \mathrm{g} / \mathrm{m}^{3}$ at increased ventilation and $514 \mu \mathrm{g} / \mathrm{m}^{3}$ at decreased ventilation, and those in building B (3 years old) were 737 and $2,353 \mu \mathrm{g} / \mathrm{m}^{3}$, respectively. The age of building $\mathrm{A}$ was similar to that of the university 
building that we measured. Notably, the TVOC concentration in building A at increased ventilation was similar to our daytime data and that at decreased ventilation was also similar to our nighttime data of the seminar room and laboratory-1 in this work, although the ventilation rates were unclear and the sampling method was different. The TVOC concentration in building B was higher than that in building $\mathrm{A}$. The VOC concentrations depend on many factors, but one possible reason for such higher TVOC concentrations is that the emission rate of VOCs in building B was relatively larger because building B is newer than building A. In both buildings, the TVOC concentration was low at a high ventilation rate and high at a low ventilation rate, which were the same tendencies seen in our results. In both cases, TVOC was low in the case of high ventilation, indicating that the ventilation is important for reducing the TVOC concentration.

In the present study, mechanical ventilation was stopped during the night, so that the TVOC concentration increased during this period. To understand the relationship between the ventilation rate and the TVOC concentration, we estimated the TVOC concentration by a simple mass balance model and compared the estimated values with the measured ones.

If the air in the room is assumed to be perfect mixing, a mass balance equation is shown as follows:

$V \frac{\mathrm{d} C}{\mathrm{~d} t}=Q C_{0}-Q C+F$,

where $V$ is the volume of room $\left(\mathrm{m}^{3}\right), C$ is the concentration $\left(\mu \mathrm{g} / \mathrm{m}^{3}\right), C_{0}$ is the TVOC concentration in the inlet air $\left(\mu \mathrm{g} / \mathrm{m}^{3}\right), t$ is the time (h), $Q$ is the ventilation air flow rate $\left(\mathrm{m}^{3} / \mathrm{h}\right)$, and $F$ is the TVOC emission rate $(\mu \mathrm{g} / \mathrm{h})$. By integrating Eq. (1) from $t=0$ to $t=t$ under initial conditions of $C=C_{\text {in }}$ at $t=0$ :

$C=\left(C_{\text {in }}-\frac{F}{Q}\right) \exp \left(-\frac{Q}{V} t\right)+\frac{F}{Q}$,

where $Q / V$ indicates the air exchange rate $\left(\mathrm{h}^{-1}\right)$.

We roughly estimated the emission rate and air exchange rate by assuming the emission rate was constant. We applied Eq. (2) to the measured data shown in Fig. 2. The calculated concentration is shown in the figure as a dashed line. In this case, the air exchange rate $(Q / V)$ was roughly estimated as $0.12 \mathrm{~h}^{-1}$ during the night and $0.9 \mathrm{~h}^{-1}$ during the day. The TVOC emission rate $(F)$ was estimated to be approximately $40 \mathrm{mg} / \mathrm{h}$. From this simulation, we estimate that a ventilation flow rate of at least $100 \mathrm{~m}^{3} / \mathrm{h}$ is needed for this room to keep the TVOC concentration below the Japanese provisional target criterion (400 $\left.\mu \mathrm{g} / \mathrm{m}^{3}\right)$.

During summer nights, the TVOC concentration in many rooms exceeded the target criterion (Figs. 3, 4).
Sakai et al. [20] reported that indoor air levels of $2 \mathrm{E} 1 \mathrm{H}$ in Japanese large-scale buildings were significantly higher during the summer than during the winter. They described the reason for this was due to hydrolysis of flooring materials. This must be one of the reasons, but in general, the emission rate of VOCs from building materials and furniture increase with an increase in temperature [13, 21]. Therefore, it is reasonable that the TVOC concentration during the summer was higher than that during the winter if the room conditions except for the temperature were identical. However, Rehwagen et al. [22] measured the VOC concentrations in German apartments, and they found that the VOC concentrations were high during the winter and low during the summer. Raw et al. [23] also measured VOC concentrations in English homes and they also reported that the TVOC concentration was high during the autumn and winter and low during the summer. They did not explain the reason for such seasonal changes on the TVOC concentration, but the differences between their results and this work may be from differences in room conditions such as ventilation systems or emission sources. If a central ventilation system is not installed in the homes and apartments, the ventilation rate during the winter should be low because the windows were mainly closed, and if residents use heaters that burn fossil fuels during the winter, this also increases the TVOC concentrations.

As shown in Fig. 3b, the TVOC concentration increased during the night and it finally exceeded $2,000 \mu \mathrm{g} / \mathrm{m}^{3}$, which was much higher than that of other samples. One reason for such a high TVOC concentration might be a large emission rate due to high temperature, because sampling was carried out during the summer (August, 8). In addition, monitoring was carried out from Friday to Saturday. In this building, the ventilation system was stopped on Saturday and Sunday, so that the emitted VOCs stagnated in the room. The TVOC concentration did not decrease, even by the next morning. The temperature was also high on August 27, but the TVOC concentration during the night was lower than that on August 8 (Fig. 4). The data are not shown, but the TVOC concentration on August 27 began to increase at 18:00, which was similar to the case on August 8. The TVOC concentration increased up to $1,150 \mu \mathrm{g} / \mathrm{m}^{3}$ at $00: 30$. However, it decreased quickly and was approximately $300 \mu \mathrm{g} / \mathrm{m}^{3}$ at 06:00. The decreasing curve was similar to that for the data after 08:00 shown in Fig. 2. The cause for this is not confirmed, but we speculate that the ventilation system was operating during this period. As shown above, because the VOC concentrations in the indoor environment easily increase when the ventilation system is stopped, natural ventilation is recommended to prevent SBS or MCS, especially during summer nights. 
Human activity may also affect the TVOC concentration. A person may be an emission source of VOCs, but the VOCs contained in materials and stationery are likely more important. For example, the high concentration of TVOC in Fig. 5 was caused by the use of a large amount of ethanol for the dissection of mice. In Fig. 3c, the TVOC concentration also increased during 09:00 to 12:00, which suggests that students or staff members entered the room and some action associated with VOC emissions may have occurred. The seminar room is small $\left(18 \mathrm{~m}^{2}\right)$ and windowless, and has numerous VOC emission sources. Students were also entering and leaving this room freely. The TVOC emission may increase when students enter the room and use equipment such as computers, printers [24] or felt-tip pens. Therefore, the VOC concentration in this room can easily increase. Because a realtime monitor can continuously detect changes in the VOC concentration, it will become a useful tool for evaluating indoor air quality.

In general, the TVOC concentrations in the seminar room and laboratory-1 were high and those in the computer rooms and the library were low (Table 1). Many chemicals are used for research experiments in laboratory-1, and staff members and students use these chemicals frequently, which can easily increase the VOC concentrations. On the other hand, the computer room and library are open even during the night and the ventilation system operates not only during the day but also at night. This may be why TVOC concentrations were generally low in these rooms. Because many students and staff members use the computer room mainly during the day, the TVOC concentration in the computer room increased more during the day than during the night.

In summary, a real-time monitor using a semiconductor gas sensor was able to monitor the TVOC concentration in indoor air with high sensitivity continuously for $24 \mathrm{~h}$. In principle, the semiconductor gas sensors cannot measure the concentrations of individual components of the VOCs, separately. In this study, there was good agreement between the values obtained by the active sampling method and those obtained by the VOC monitor. However, when using the sensor to measure the presence of VOCs with extremely low or high sensitivity, the values measured by the VOC monitor may be different from the actual TVOC concentration. Therefore, data on the sensitivity of the sensor for many different VOCs should be collected in future investigations.

Acknowledgments The authors thank Ms. Nanako Hara for technical help. This work was partly supported by a Grant-in-Aid for Scientific Research from the Japan Society for the Promotion of Science (JSPS).

\section{Conflict of interest None.}

\section{References}

1. The Ministry of Health, Labour and Welfare. Committee on sick house syndrome. Indoor air pollution progress report no. 4summary on the discussions at the 8th and 9th meetings; 2002. http://www.nihs.go.jp/mhlw/chemical/situnai/kentoukai/rep-eng4. html.

2. The Ministry of Education, Culture, Sports, Science and Technology, Japan, Notice to amendment of criteria of school environmental health; 2002 (in Japanese).

3. International Organization for Standardization. ISO 16000-3: 2001. Indoor air-part 3: determination of formaldehyde and other carbonyl compounds-active sampling method; 2001.

4. International Organization for Standardization. ISO 16000-6: 2004. Indoor air-part 6: determination of volatile organic compounds in indoor and test chamber air by active sampling on Tenax TA sorbent, thermal desorption and gas chromatography using MS/FID; 2004.

5. Héroux M-E, Clark N, Ryswyk KV, Mallick R, Gilbert NL, Harrison I, et al. Predictors of indoor air concentrations in smoking and non-smoking residences. Int J Environ Res Public Health. 2010;7:3080-99.

6. Woebkenberg ML, McCammom CS. Direct-reading gas and vapor instruments. In: Cohen BS, Herng SV, editors. Air sampling instruments for evaluation of atmospheric contaminants. Chap. 19. Cincinnati: ACGIH, 1995. p. 439-510.

7. Oka K, Iizuka A, Inoue Y, Mizukoshi A, Noguchi M, Yamasaki A, Yanagisawa Y. Development of a combined real time monitoring and integration analysis system for volatile organic compounds (VOCs). Int J Environ Res Public Health. 2010;7:4100-10.

8. Bruno P, Caselli M, de Gennaro G, Iacobellis S, Tutino M. Monitoring of volatile organic compounds in non-residential indoor environments. Indoor Air. 2008;18:250-6.

9. Kamijima M, Sakai K, Shibata E, Yamada T, Itohara S, Ohno H, et al. 2-Ethyl-1-hexanol in indoor air as a possible cause of sick building symptoms. J Occup Health. 2002;44:186-91.

10. Sakai K, Kamijima M, Shibata E, Ohno H, Nakajima T. Indoor air pollution by 2-ethyl-1-hexanol in non-domestic buildings in Nagoya, Japan. J Environ Monit. 2005;8:1122-8.

11. Ernstgård L, Norbäck D, Nordquist T, Wieslander G, Wålinder R, Johanson G. Acute effects of exposure to $1 \mathrm{mg} / \mathrm{m}^{3}$ of vaporized 2-ethyl-1-hexanol in humans. Indoor Air. 2010;20:168-75.

12. Menzies D, Tambyn RM, Fatima Nunes F, Hanley J, Tamblyn RT. Exposure to varying levels of contaminants and symptoms among workers in two office buildings. Am J Pubic Health. 1997;86:1629-33.

13. Hori H, Morita I, Otoguro T, Higashi T. Measurement of emission rate of formaldehyde and volatile organic compounds (VOCs) from construction materials by the small chamber method. J UOEH. 2003;25:283-94. (in Japanese).

14. Ishidao T, Ishimatsu S, Hori H. Measurement of volatile organic compounds concentrations in indoor air of school buildings in a university. J Work Environ. 2004;25:66-71. (in Japanese).

15. Ishidao $\mathrm{T}$, Ishimatsu $\mathrm{S}$, Hori $\mathrm{H}$. Measurement of volatile organic compounds concentration in indoor air of school buildings in an university (part 2). J Work Environ. 2005;26:52-7. (in Japanese).

16. Norbäck D, Torgén M, Edling C. Volatile organic compounds, respirable dust, and personal factors related to prevalence and incidence of sick building syndrome in primary schools. Br J Ind Med. 1990;47:733-41.

17. Hori M. Total volatile organic compound (TVOC) as indicator of indoor air quality. Indoor Environ. 2010;13:9-19.

18. Fine GF, Cavanagh LM, Afonja A, Binions R. Metal oxide semiconductor gas sensors in environmental monitoring. Sensors. 2010;10:5469-502. 
19. Ho DX, Kim KH, Sohn JR, Oh YH, Ahn JW. Emission rates of volatile organic compounds released from newly produced household furniture products using a large-scale chamber testing method. Sci World J. 2011;11:1597-622.

20. Sakai K, Kamijima M, Shibata E, Ohno H, Nakajima T. Annual transition and seasonal variation of indoor air pollution levels of 2-ethyl-1-hexanol in large scale buildings in Nagoya, Japan. J Environ Monit. 2009;11:2068-76.

21. Van der Wal JF, Hoogeveen AW, Wouda P. The influence of temperature on the emission of volatile organic compounds from PVC flooring, carpet, and paint. Indoor air. 1997;7:215-21.
22. Rehwagen M, Schlink U, Herbarth O. Seasonal cycle of VOCs in apartments. Indoor Air. 2003;13:283-91.

23. Raw GJ, Coward SKD, Brown VM, Crump DR. Exposure to air pollutants in English homes. J Exp Anal Environ Epidemiol. 2004;14:S85-94.

24. Kagi N, Fujii S, Horiba Y, Namiki N, Ohtani Y, Emi H, Tamura $\mathrm{H}$, Kim YS. Indoor air quality for chemical and ultrafine particle contaminants from printers. Build Environ. 2007;42:1949-54. 